\title{
Auditory Properties in the Parabelt Regions of the Superior Temporal Gyrus in the Awake Macaque Monkey: An Initial Survey
}

\author{
Yoshinao Kajikawa, ${ }^{1}$ Stephen Frey, ${ }^{2}{ }^{-}$Deborah Ross, ${ }^{1}$ Arnaud Falchier, ${ }^{1}$ Troy A. Hackett, ${ }^{3}$ and Charles E. Schroeder ${ }^{1,4}$ \\ ${ }^{1}$ Cognitive Neuroscience and Schizophrenia Program, Nathan S. Kline Institute for Psychiatric Research, Orangeburg, New York 10962, ${ }^{2}$ Rogue Research, \\ Inc., Montreal, Quebec, H2W 1 Z5 Canada, ${ }^{3}$ Department of Hearing and Speech Sciences, Vanderbilt University, Nashville, Tennessee 37203 , and \\ ${ }^{4}$ Department of Psychiatry, Columbia University College of Physicians and Surgeons, New York, New York 10032
}

The superior temporal gyrus (STG) is on the inferior-lateral brain surface near the external ear. In macaques, $2 / 3$ of the STG is occupied by an auditory cortical region, the "parabelt," which is part of a network of inferior temporal areas subserving communication and social cognition as well as object recognition and other functions. However, due to its location beneath the squamous temporal bone and temporalis muscle, the STG, like other inferior temporal regions, has been a challenging target for physiological studies in awakebehaving macaques. We designed a new procedure for implanting recording chambers to provide direct access to the STG, allowing us to evaluate neuronal properties and their topography across the full extent of the STG in awake-behaving macaques. Initial surveys of the STG have yielded several new findings. Unexpectedly, STG sites in monkeys that were listening passively responded to tones with magnitudes comparable to those of responses to $1 / 3$ octave band-pass noise. Mapping results showed longer response latencies in more rostral sites and possible tonotopic patterns parallel to core and belt areas, suggesting the reversal of gradients between caudal and rostral parabelt areas. These results will help further exploration of parabelt areas.

Key words: auditory cortex; electrophysiological recordings; macaque monkey; mapping; parabelt; superior temporal gyrus

\section{Introduction}

Auditory cortex in primates is arranged in a "core" of primary areas surrounded by "belt" of secondary areas (Kaas and Hackett, 2000), further bound laterally by tertiary "parabelt" region that occupies the posterior $2 / 3$ of the superior temporal gyrus (STG) (Hackett et al., 1998a). The parabelt (PB) region is divided into two areas, the rostral (RPB) and the caudal (CPB), which receive auditory inputs from belt areas hierarchically and directly from extralemniscal thalamic nuclei (Hackett et al., 1998b). The RPB and $\mathrm{CPB}$ are preferentially connected with rostral and caudal belt areas, respectively (Hackett et al., 1998a), and to ventral and dorsal prefrontal cortices (Hackett et al., 1999; Romanski et al., 1999b; Munoz-Lopez et al., 2010), suggesting their differential involvement in auditory processing streams (Romanski et al., 1999a; Rauschecker and Tian, 2000). RPB and CPB connections

Received Aug. 25, 2014; revised Jan. 29, 2015; accepted Feb. 1, 2015.

Author contributions:Y.K., S.F., T.A.H., and C.E.S. designed research; Y.K., S.F., and D.R. performed research; Y.K., S.F., D.R., and A.Y.F. contributed unpublished reagents/analytic tools; Y.K. and A.Y.F. analyzed data; Y.K., T.A.H., and C.E.S. wrote the paper.

This work was supported by the National Institutes of Health (Grants R21DC012918, R01 DC04318, and R01 DC011490). We thank C. Hu and R. Sangoi for assisting MRI and T. McGinnis, M.N. O'Connell, and M. Klinger for surgical assistance and veterinary care.

S.F. is a paid employee of Rogue Research, Inc., and owns stock in the company. The remaining authors declare no competing financial interests.

Correspondence should be addressed to Yoshinao Kajikawa, Nathan Kline Institute, 140 Old Orangeburg Rd, Orangeburg, NY 10962. E-mail:ykajikawa@nki.rfmh.org.

DOI:10.1523/JNEUROSCI.3556-14.2015

Copyright $\odot 2015$ the authors $\quad 0270-6474 / 15 / 354140-11 \$ 15.00 / 0$ with pulvinar, striatum, and amygdala suggest roles in attention, emotion, and response selection (Romanski et al., 1997).

In humans, the anterior and posterior portions of auditory cortex, which include the putative belt and parabelt regions, are proposed to segregate into anterior "what" and posterior "where" streams (Ahveninen et al., 2006; Rauschecker and Scott, 2009) and to mediate speech and auditory object processing (Binder et al., 2004; Leaver and Rauschecker, 2010; Mesgarani et al., 2014), audiovisual integration (Calvert et al., 1997; Johnson and Zatorre, 2005), and auditory working memory (Buchsbaum et al., 2005; Leff et al., 2009). However, the anatomical definition of human parabelt is still uncertain. Cytoarchitectonic and chemoarchitectonic criteria established in monkeys identified putative parabelt in the planum temporale portions of area 22 on the STG (Sweet et al., 2005; Fullerton and Pandya, 2007; Hackett, 2008). fMRI studies variably located parabelt areas on the upper bank of the superior temporal sulcus and belt areas on STG and planum temporale (Humphries et al., 2010; Woods et al., 2010; StriemAmit et al., 2011). Physiological characterization of monkey parabelt may help in solving this ambiguity.

Relatively little is known about auditory response properties in the macaque STG. An early study in awake monkeys showed that neurons in the caudal STG (temporal parietotemporal area and possibly $\mathrm{CPB}$ ) respond to a wide variety of natural sounds as well as pure tones and some to visual and/or somatosensorymotor events (Leinonen et al., 1980). These findings, along with the reported sensitivity to auditory attention in putative human 
parabelt, suggest that that macaque parabelt is a higher-order auditory-integrative region with complex response properties (Petkov et al., 2004; Woods et al., 2009). However, due to its anatomical location and poor responsiveness under anesthesia, the basic auditory response properties of parabelt neurons have been sampled only sparsely (Leinonen et al., 1980; Camalier et al., 2012), and no systematic studies have been done so far. The purpose of present study was to establish techniques for long-term recordings from parabelt in awake-behaving macaques and to characterize the basic auditory responses of macaque parabelt. Our results raise the possibility that parabelt areas have organized spectral representations that may parallel those in the lower belt and core areas.

\section{Materials and Methods}

Animals

Ten rhesus monkeys (Macaca mulatta) participated in MRI, two of which (A, female and B, male) were surgically implanted with recording chambers targeting the STG in the left hemisphere. All experimental procedures were approved by the Institutional Animal Care and Use Committee of the Nathan Kline Institute.

\section{MRI and image analyses}

MRI. All animals were scanned with a Siemens 3T TRIO TIM MRI System with software version VB17A (Siemens Medical Systems) with a "transmit-receive 8-channel knee coil." Animals were anesthetized with same procedures as in the "Surgeries" section (see below) and placed in a supine position on the scanning table. The monkeys' heads were stabilized within the imaging coil using soft padding spacers. 3D highresolution structural images were obtained with the MPRAGE scan: $256 \times 256$ matrix, FOV $12.8 \times 12.8 \mathrm{~cm}$., slice thickness $1.0 \mathrm{~mm}$, slice gap $=0 \mathrm{~mm}$. Scans were acquired in sagittal, horizontal, and coronal planes.

MRI analyses. MRIs of the 10 animals were analyzed individually for the STG position relative to the zygomatic arch (ZA) to examine the feasibility of STG chamber implantation (see Fig. $1 A, B$ ). Positions of landmarks: the lateral sulcus (LS) and the superior temporal sulcus (STS), critical for identifying the location of STG, were calculated as follows. Grayscale MRIs of sagittal planes that contained the LS, the STS, or the ZA were converted to TIFF and each of these structural features was outlined in red (magenta in Fig. 1), green, and blue (cyan in Fig. 1) contour lines along the middle of LS, STS, or the upper edge of ZA, respectively. TIFF images including those lines were then read by MATLAB to detect the positions of colored lines within those images by appropriate threshold detection for each color. Those positions were transformed to stereotaxic coordinates that would be used for the surgery to implant recording chambers aiming at STG. Due to the idiosyncratic alignment of MRIs of the head in stereotaxic axes, translations and rotations of landmark positions were necessary.

We identified the center of both ear canals and calculated the midpoint in 3D that corresponded to the origin of the stereotaxic axes (Fig. $1 A, B$ ). We also identified the infra-orbital rim of each eye socket; these corresponded to the contact points of eye bars during stereotaxic surgeries and, together with the stereotaxic origin, form the plane $D V=0$. Next, to correct for misalignments of these landmarks due to variable positioning of the head relative to the angles of MRI scan, we subtracted the coordinate of the stereotaxic origin from the coordinates of eye and calculated a 3D matrix. This matrix rotated eye position around the stereotaxic origin to align infra-orbital rim positions at the same height as the origin. Finally, we calculated another rotation matrix to align infraorbital positions symmetrically about the sagittal plane that contained the stereotaxic origin.

Subsequently, the positions of LS, STS, and ZA were identified as follows. In images of sagittal sections, the above landmarks were traced through each image. The coordinates of the landmarks (tracings) were identified and the stereotaxic origin was subtracted to compensate for translation. The tracings were rotated to correct for roll, pitch, and yaw angles using the rotation matrices described above. The subsequent co- ordinates were all placed in reference to the stereotaxic origin along the axes that would be the reference during the chamber implantation surgery.

\section{Manufacturing of the custom chamber}

The high-resolution T1 MRI images were loaded into the Brainsight software (Rogue Research) and used to create 3D reconstructions of the skin, skull, and brain in Monkey B. In addition to the identification of the interaural plane, the brain was coregistered to the Paxinos rhesus stereotaxic coordinates (Paxinos et al., 2008) and the MNI rhesus macaque monkey space (Frey et al., 2011). The approximate boundaries of the auditory cortex were identified (core, belt, and parabelt) on the MRI images and the $3 \mathrm{D}$ brain reconstructions. A rectangular-shaped computer-aided design (CAD) chamber file was then loaded into the software and placed over the key areas of the STG (see Fig. $2 A$ ), conforming to the skull (see Fig. 2B). The intersection of the skull surface and the CAD chamber file was clipped and saved as a new CAD file, which was then transformed into a solid model file using Solidworks software. A simultaneous five-axis machine was then used to create the titanium chamber after the solid model file was converted to computer-aided manufacturing software. After manufacturing, the underside of the chamber and legs was sand blasted to increase osseointegration of the implanted part.

\section{Surgeries}

All surgical procedures were performed using aseptic techniques. Animals were sedated with ketamine hydrochloride $(10-15 \mathrm{mg} / \mathrm{kg}, \mathrm{IM})$, atropine, and diazepam, followed by intravenous infusion of saline and intubation. Anesthesia was maintained with a mixture of isoflurane (1$2 \%)$ and $\mathrm{O}_{2}$. Body temperature was maintained at $37-38^{\circ} \mathrm{C}$ with a heating pad. Vital signs (blood pressure, heart rate, body temperature, oxygenation, and end tidal $\mathrm{CO}_{2}$ ) were monitored throughout the surgery and used to adjust anesthetic depth. Limb withdrawal and palpebral reflexes were measured to insure that the level of anesthesia was sufficient before placing the animal in the stereotaxic frame. The animal's head was fixed in a stereotaxic frame using raised ear and eye bars (David Kopf Instruments). The use of raised bars provided more space above the stereotaxic frame to expose the STG, which would be only a few millimeters above the height of the ear bars.

Monkey A. As an initial test of the feasibility of a direct lateral approach to the STG, Monkey A (a 5-year-old female, $7.3 \mathrm{~kg}$ ) was implanted with a CILUX recording chamber (inner dimension: $20 \times 20 \mathrm{~mm}$, Crist Instrument) targeting the left STG, along with standard head fixation devices (for chronic-awake recording). After the head was affixed to the frame and the exposed skin of the surgical area was cleaned, a midline incision was made to expose the skull. The left temporalis muscle was detached from the temporal line and retracted laterally until the skull exposure reached the zygomatic process. Two Synthes plates were used as anchors for pedestal/headpost integrity and were implanted using Synthes selftapping screws at positions anterior and posterior to the area of the craniotomy (AP 3-23 mm, DV 8-28 mm) for the STG chamber. To fully visualize the skull in preparation for the craniotomy, a partial incision of the temporalis muscle was made. The anterior and posterior portions of the medial edge of the muscle were separated to create a space in which to place the chamber. Retractors were used to keep the remainder of the temporalis muscle under tension and two Synthes plates were implanted using $6 \mathrm{~mm}$ Synthes self-tapping screws at positions anterior and posterior to the area of the craniotomy (i.e., AP 3-23 mm, DV 8-28 mm) for the STG chamber. The craniotomy was made using a dental drill and 2.1 $\mathrm{mm}$ and $0.7 \mathrm{~mm}$ micro burrs (Fine Science Tools). A chamber cap was used to place and hold the chamber. The chamber was initially secured using a small "gasket" of Versabond (Smith and Nephew) bone cement. The bottom section of the chamber was slanted so as to produce an upward angle of 25 degrees. Additional bone cement was used to integrate the original "gasket" and the anterior and posterior Synthes plates. After the cement was cured, the cap of the chamber was released. The ventral portion of temporalis muscle was repositioned below the chamber. The remainder of the temporalis muscle was covered by the temporal fascia and bone cement was used to ensure a smooth wound margin 
between the superior part of the external ear and the acrylic pedestal. The chamber was flushed to ensure it was sterile and water-tight before the surgery was completed.

Though we obtained successful access to STG with Monkey A's procedure (Fig. 2E), the entire preparation was cumbersome due to the size and shape of the implant. For example, some minor deformation of the external ear in this animal was inevitable due to the size of the acrylic pedestal surrounding the STG chamber. Note that this did not obstruct the ear canal.

Monkey B. Using the information gained from Monkey A, we designed a custom chamber that provided improved access, reduced bulk, and improved tissue interface by eliminating the use of bone cement. Monkey B (a 6-year-old male, $12 \mathrm{~kg}$ ) underwent an initial surgery to implant a headpost. After scalp healing and osseointegration was complete (8 weeks), a custom titanium chamber with 5 feet (Rogue Research) was implanted during a second surgery. The chamber was affixed to the skull by Synthes titanium screws through each foot. To better target the STG perpendicularly, this chamber was designed based on the presurgical MRI to fit the surface of the animal's skull (Fig. 2B). The chamber had an inner dimension of $15 \times 20 \mathrm{~mm}$ with coordinates measuring [ -0.5 11.5], [3.7 25.9], [18.7 5.9], and [22.9 20.3] ([AP, DV] mm) of the inner corners.

After the surgical preparation in the stereotaxic frame, a parasagittal incision was made on the left hemisphere approximately above the temporal line. The medial and lateral skin edges were retracted to expose the temporalis muscle. The temporalis muscle was retracted laterally from the temporal line while leaving the anterior and posterior attachments intact. A medial-to-lateral incision of the lateral skin was made to fully expose the skull. The temporalis muscle was cauterized vertically at two points ( $\sim$ AP 2 and $21 \mathrm{~mm}$ ) and the segment in between (i.e., $\sim>$ DV 6 $\mathrm{mm}$ ) was removed (Fig. $2 \mathrm{C}$ ). The remaining anterior and posterior muscle tissue was kept moist with saline sponges and placed under retraction. The recording chamber was placed onto the skull and screw holes were drilled at the positions of the chamber feet and then fixed with Synthes self-tapping screws. The edges created by the feet of the chamber were covered by Mi-Mix calcium phosphate bone cement (Biomet Microfixation). The inner wall of the chamber was also sealed to the skull using Mi-Mix cement. The anterior and posterior muscle lobes were placed to flank the anterior and posterior aspects of the chamber (Fig. 2D). The chamber was then flushed with saline and $0.5 \mathrm{cc}$ of Baytril (Butler Schein) as a final rinse. The chamber was then partially filled with SILASTIC (Dow Corning) to preserve the integrity of the bone because the craniotomy was not being opened at the time of the chamber implant. The lateral skin was pulled up to cover the chamber and the skin covering the rectangle portion on the rim of the chamber was excised to provide a tight tissue edge around the chamber. The remaining skin was draped over the temporalis muscle as close to the original position as was possible. The lateral and medial skin edges were sutured to close the wound.

Unlike Monkey A (female), a portion of the temporalis muscle of Monkey B (male) was removed rather than being displaced downward by the implant. Therefore, the external ear of Monkey B was relatively normal (Fig. 2F). We also reduced the height of the custom chamber to 20 $\mathrm{mm}$ during manufacturing so as to reduce acoustic interference.

In both monkeys, longer screws ( $8 \mathrm{~mm}$ ) were used in the supramastoid crest, the temporal bone posterior to the chambers where the bone is thicker.

In Monkey B, the craniotomy was performed $\sim 6$ weeks after initial implantation of the STG chamber. The SILASTIC was removed and the inside of the chamber was sterilized using betadine and saline before initiating the surgery. Initial access $(\sim 4 \times 4 \mathrm{~mm})$ was gained using a dental drill with a $2.1 \mathrm{~mm}$ microburr (Fine Science Tools). Once we had removed this small section of bone, we used a 7 inch Kerrison rotating rongeur with a $2 \mathrm{~mm}$ bite to remove the majority of the bone within the STG chamber. We ensured that the edges of the craniotomy were smooth using the Foredom drill with a $0.7 \mathrm{~mm}$ micro burr (Fine Science Tools). The chamber was flushed to ensure it was sterile and remained watertight before the surgery was completed. The chamber was then flushed with $0.5 \mathrm{cc}$ of Baytril (Butler Schein) as a final rinse.
Postsurgery behavior. After the implant surgery, both Monkey A and Monkey B were offered "wet" chow (soft fruits and vegetables, etc.) and both animals started to eat food normally within a few days. Monkey B has been trained for behavioral tasks before surgeries (not reported yet). His performance on the tasks was comparable before and after surgery.

\section{Stimulus presentation}

Tones and noises were delivered binaurally through two individually calibrated, free field speakers (TDT) placed 4 inches from both ears. Tone frequencies and center frequencies of band-pass noise (BPN) ranging from $353.55 \mathrm{~Hz}$ to $32 \mathrm{kHz}$ with 0.5 octave intervals (14 frequencies) and broad-band noise $(\mathrm{BBN})$ were presented in a quasirandom order at $60 \mathrm{~dB}$ SPL (duration: $100 \mathrm{~ms}$, SOA: $625 \mathrm{~ms}$ ). For Monkey A, an additional battery of sounds including click trains, linear frequency modulation sweeps, amplitude-modulated noise, vocal sounds, and other natural sounds were also presented passively. To ensure attention to the stimuli, Monkey B was trained to perform auditory and audiovisual discrimination tasks using a different set of stimuli including movie clips of conspecific vocalization. Sites unresponsive to any sound but responsive to macaque face images during the audiovisual tasks were defined as sites of activity related to visual events (see Fig. $4 B$ ). Two sites unresponsive to sounds but that had elevated activity when aqueous reward was delivered during tasks were defined as the sites of activity related to somatosensorymotor events (see Fig. 4B). The influences of the behavioral task are under continuing study in an additional study and will be presented in a subsequent report.

\section{Electrophysiological recordings and data analysis}

Recordings. All electrophysiological recordings were completed while monkeys were awake and sitting quietly in a standard monkey chair (Crist Instruments). Reference electrodes were positioned in saline in the chamber above the dura. The electrodes (Plexon U-probes) consisted of a linear array with 23 contacts $(0.3-0.5 \mathrm{M} \Omega$ at $1.0 \mathrm{kHz})$ spaced either 0.1 or $0.2 \mathrm{~mm}$ apart. Electrode penetrations were made on a grid of $1 \mathrm{~mm}$ intervals. The field potentials (FPs; $0.1 \mathrm{~Hz}-500 \mathrm{~Hz}$ ) and multiunit activity (MUA: $200-5000 \mathrm{~Hz}$, further band-pass, zero phase shift digital filtering $300-3000 \mathrm{~Hz}, 48 \mathrm{~dB} /$ octave and rectifying) were recorded from each contact. From the simultaneously recorded FPs, current source density (CSD) was also calculated to estimate the distributions of synaptic activity. Based on laminar CSD patterns, current sinks corresponding to granular, supragranular, and infragranular layers were identified (Kajikawa and Schroeder, 2011, 2015).

Data analysis. At all recording sites, signals were averaged over 40 or more trials for each sound. For each recording site, the presence of significant responses was determined as follows. The timing of response peak was derived from the MUA responses at or near the granular layer averaged across all trials and response period was defined around its peak timing ( $\pm 5 \mathrm{~ms}$ or longer for sluggish slow responses). Response magnitude for each trial was calculated by subtracting the baseline mean amplitude ( $\sim 50$ to $\sim 0 \mathrm{~ms}$ from the stimulus onset) from the mean MUA amplitude during the response period. Averages of magnitudes across all trials that were significantly above zero (bootstrap, 1000 resample, $p<$ 0.05 , two-tailed) were considered as responses. For each site, the best frequency $\left(\mathrm{BF}_{\text {Tone }}\right)$ was identified as the frequency of tone that evoked the largest significant MUA response. Similarly, BF of responses to BPN $\left(\mathrm{BF}_{\mathrm{BPN}}\right)$ was identified. The latency of responses to $\mathrm{BBN}$ was derived from the mean MUA across trials as the shortest delay from the onset of sound that MUA exceeded the threshold level defined from the baseline period (mean plus 3 times the SD).

Topographic pattern analysis. We tested for the presence of clusters of similar BF statistically. Based on the BFs of sites included in the present study (see Fig. $5 E, F)$, sites were sorted into groups of low $\mathrm{BF}(2.8 \mathrm{kHz}$ or low) and high $\mathrm{BF}$ ( $4 \mathrm{kHz}$ or higher). If there were clusters of low and high $\mathrm{BF}$ sites, a location surrounded by high or low BF sites was likely to represent high or low $\mathrm{BF}$, respectively. In other words, the probability of a site being high or low $\mathrm{BF}\left(p_{\mathrm{HIGH}}\right.$ or $\left.p_{\mathrm{LOW}}=1-p_{\mathrm{HIGH}}\right)$ is high. On the other hand, if topographic pattern of $\mathrm{BF}$ is random, it is likely that every site is surrounded by both high and low $\mathrm{BF}$ sites and that both $p_{\mathrm{HIGH}}$ and $p_{\mathrm{LO}}$ are at the chance level (e.g., probability $=0.5$ ) at every site. Such randomness in topographic 
pattern of categorized groups results in large entropy, $H$, quantified by the sum of $-p_{\text {HIGH }} \log _{2}\left(p_{\text {HIGH }}\right)$ and $-p_{\text {LOW }} \log _{2}\left(p_{\text {LOW }}\right)$ over all sites.

We calculated maps of $p_{\mathrm{HIGH}}$ and $p_{\mathrm{LOW}}$ as follows. High and low BF sites were assigned a value 1 and 0 , respectively. Convolution of such binary-valued maps with 2D volume-normalized Gaussian distribution (SD of $1 \mathrm{~mm}$ same as the grid intervals in both dorsal-ventral and anterior-posterior dimensions) resulted in the $p_{\mathrm{HIGH}}$ maps in which domains of high and low BF cluster, if present, had values of probability larger and smaller than 0.5 . For random maps in which high and low BF sites ( 1 and 0 ) are intermingled or equally likely around every site, the values of the distributed probability are near 0.5 . In calculating these maps, sites that were neither tested for tone responses nor tone-responsive were not included in derivation of $p_{\mathrm{HIGH}}$ by convolution and did not take $p_{\mathrm{HIGH}}$ values. The $p_{\mathrm{LOW}}$ map was obtained by $1-p_{\mathrm{HIGH}}$ from its counter map of $p_{\mathrm{HIGH}}$. Given maps of $p_{\text {HIGH }}$ and $p_{\text {LOW }}$, entropy of topographic maps were calculated as follows: $H=\sum_{k}-p_{\mathrm{HIGH}}^{\mathrm{k}} \log _{2}\left(p_{\mathrm{HIGH}}^{\mathrm{k}}\right)-p_{\mathrm{LOW}}^{\mathrm{k}} \log _{2}\left(p_{\mathrm{HIGH}}^{\mathrm{k}}\right)$, in which $k$ indexes the tone-responsive sites.

To test the presence of clustered high and low BF domains, we set the null hypothesis that topographic patterns are random. Hypothesis testing was to examine whether $H$ of the observed pattern was as large as those of random patterns. The value of the entropy $H$ could range from 0 for complete segregation of high and low BF clusters to a value same as the number of sites for the case of uniformly random mixtures or alternating configurations of high and low BF. However, spatially sparse sampling isolates some sites from others and reduces the $H$ value because Gaussian convolutions cannot operate to adjust $p_{\mathrm{HIGH}}$ and $p_{\mathrm{LOW}}$ from 1 and 0 to intermediate values. The distribution of $H$ for random distributions was derived by calculating $H$ for 1000 topographic patterns permuted of the positions of BF.

To analyze topographic patterns of $\mathrm{BF}_{\mathrm{T} o n e}$ and $\mathrm{BF}_{\mathrm{BPN}}$ along (posterior to anterior) STG and tone response latencies along and across (dorsal to ventral) STG, we fit circular curves to the positions of recording sites that take into account the shape of the STG from posterior to anterior, as a partial lower right quadrant arc the radian of which changes from 0 to $-\pi / 2$ (see Fig. 6). Curves were fit using Taubin's method (Chernov, 2010). By projecting the recording sites on the arc radially, positions of sites were expressed in the format of polar coordinates of angle and radius, corresponding to the anterior-to-posterior and dorsal-to-ventral dimensions of STG, respectively.

To derive the mean BF curves along STG (see Fig. $6 B, C$ ), the angular positional range of recording sites for each monkey was divided into 18 bins of equal sizes. For each bin, the mean BF was estimated from the BF of all sites contained within a 3 bin window ( 2 bin window for the most caudal and rostral bins).

\section{Histology}

After mapping of STG was completed, Monkeys A and B were deeply anesthetized by a lethal dose $(100-200 \mathrm{mg} / \mathrm{kg})$ of sodium pentobarbital. Just before cardiac arrest, the animal was perfused intracardially with saline (room temperature), followed by $4 \mathrm{~L}$ of ice-cold $4 \%$ paraformaldehyde in $0.1 \mathrm{M}$ phosphate buffer. The brain was removed, photographed, and placed in buffered (30\%) sucrose for 1-2 weeks. Coronal sections $(40 \mu \mathrm{m})$ were cut and immunostained for the neuronal marker NeuN (Hackett and de la Mothe, 2009; Hackett et al., 2014).

\section{Results}

\section{Location of the STG}

The STG is on the lateral-inferior brain surface, flanked above by the LS and below by the STS. Figure $1, A$ and $B$, shows parasagittal MRIs of the head of one monkey. The STS is $\sim 20 \mathrm{~mm}$ above the center of ear canal and $\sim 10 \mathrm{~mm}$ above ZA over AP $0-20 \mathrm{~mm}$. To estimate the reliability of this positioning, we first analyzed structural MRI from 10 macaques to examine the relative positions of the STS, LS, and ZA relative to the stereotaxic landmarks (inferior rim of eye socket and ear canal). The results are summarized for the left (Fig. 1C) and right hemispheres (Fig. 1D). Across our sample of 10 animals, the STS, the inferior edge of STG, was minimally $4 \mathrm{~mm}$ above the ear canal and ZA. The positions of the
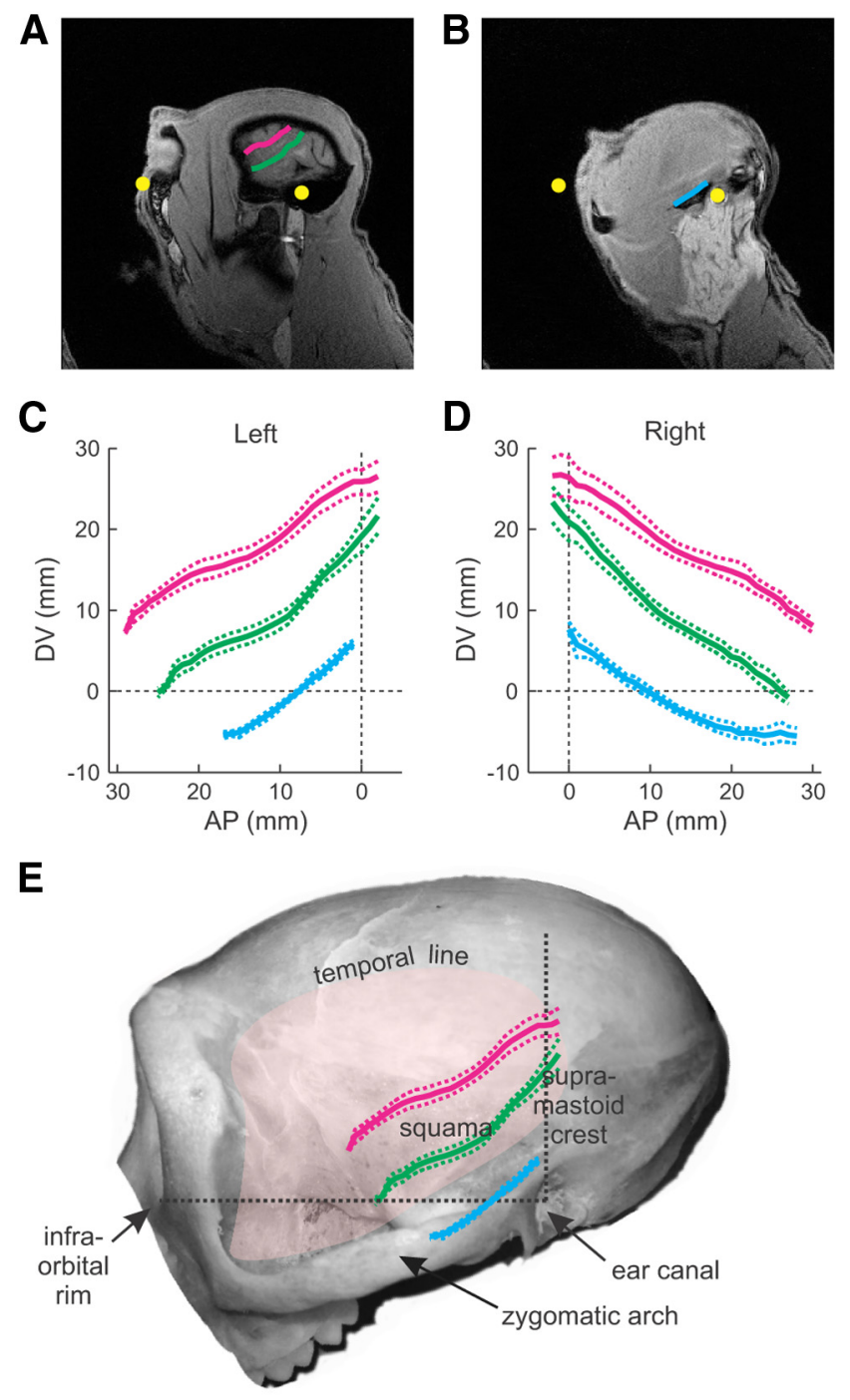

Figure 1. $A, B$, Sagittal MRI of Monkey $B$. Left is anterior. Two yellow dots indicate positions of the infra-orbital rim for the left eye socket (anterior) and the center of the left exterior auditory meatus (posterior). The two lines in $\boldsymbol{A}$ are drawn along the left LS (magenta) and STS (green). The line in $\boldsymbol{B}$ (cyan) is along the ZA. $\boldsymbol{C}$, Mean coordinates ( $n=10)$ of LS (magenta), STS (green), and ZA (cyan) relative to the position of ear bar in sagittal plane on the left hemisphere. Dotted lines are $95 \%$ confidence intervals (bootstrap, 1000 resample). D, Same as C but for the right hemisphere. $\boldsymbol{E}$, Position of the STG relative to the overlying skull surface and musculature. Pink area depicts the typical extent of the temporalis muscle up to its tendonous insertion along the "temporal line." Dotted black lines depict the vertical and horizontal zero stereotaxic axes. Magenta and green lines depict the average locations of the LS and STS bracketing the STG in relation to the position of the $Z A$ as reconstructed using structural MRIs in 10 monkeys. Dotted lines represent confidence intervals. See text for further details.

LS, STS, and ZA thus derived are transposed in stereotaxic coordinates onto the skull of a single subject (Fig. 1E). This exercise confirmed the feasibility of positioning a recording chamber over the squama above and anterior to ear canal and above the ZA throughout most its A-P extent.

Access to the STG is complicated by the complex structure of the temporal bone; the STG lies beneath the squama, the smooth convex surface of the anterior aspect of the temporal bone, and slightly above the ZA. The temporalis muscle attaches at the temporal line above the squama and passes over the squama through $\mathrm{ZA}$ and attaches to the mandible. The masseter muscle extends inferiorly from the ZA and also attaches to the mandible: both muscles are important for chewing. Posteriorly, the ZA continues 

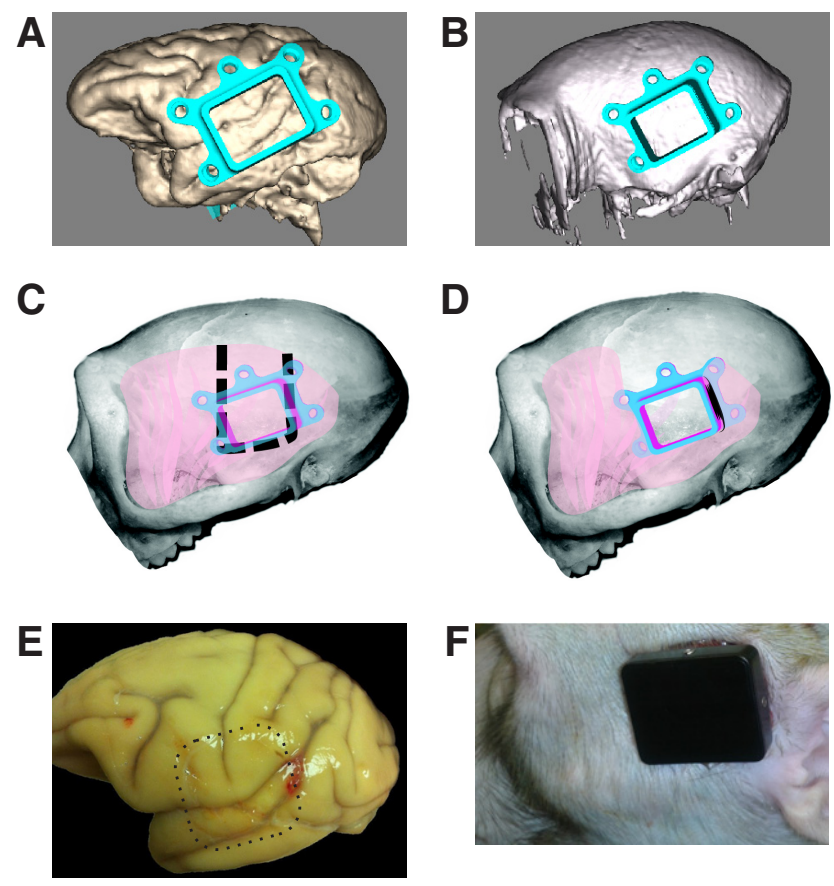

Figure 2. $\quad \boldsymbol{A}, \boldsymbol{B}$, Blueprints of custom-made chamber on the brain $(\boldsymbol{A})$ and skull $(\boldsymbol{B})$ of Monkey B. C, Schematic drawing of the intact temporalis muscle superimposed on a skull with a model of the custom-chamber at its approximate final position. The approximate dimension of cauterization is indicated by dashed black line. $\boldsymbol{D}$, Schematic drawing of the cauterized temporalis muscle in its approximated final position after the implant surgery. The muscle flanks the implanted recording chamber anteriorly and posteriorly. E, Side view of the brain of Monkey A. Dotted gray line circumscribes the rim of the bottom of the implanted chamber. $\boldsymbol{F}$, Side view of Monkey B's head after implant.

to become the supramastoid crest, the interior of which is formed with hollow cells. The ridge of the crest runs upward to surpass the posterior part of STG and then shifts anteriorly to form the temporal line. This ridge line is the upper-posterior tendon insertion of the temporalis muscle. Immediately inferior to the crest is the tympanic portion of the temporal bone that houses the external ear meatus. A craniotomy to expose the STG and adjacent inferior temporal regions is challenging because of its proximity to the ZA. In addition, such a craniotomy must avoid damage to the external ear and the posterior temporal bone, as well as deformation the external ear (which would interfere with the external ear acoustics). Our approach was to tenotomize and remove the posterior portion of the temporalis muscle and to confine the craniotomy to the squama, which is relatively thin and devoid of complex intrabone structure, while taking care to spare the ZA and the temporal bone posterior to the squama.

\section{Electrophysiological recordings from STG}

We implanted chronic recording chambers over the left STG in two monkeys (Fig. 2). Both monkeys were also implanted with headposts to permit restraint of the head during chronic awake recordings. After recovery from surgeries, both monkeys underwent electrophysiological recordings from the STG using the 23 channel linear array multielectrodes with 100 or 200 micron intercontact spacing. These "laminar" electrodes allowed simultaneous recordings from all cortical layers at each penetration site (Fig. 3). For superficial cortical regions such as the STG, the electrode arrays are lowered into a position straddling the zone of active cortical tissue as defined by the response to broad-band noise. Because this "active zone" (large current sources and sinks
A

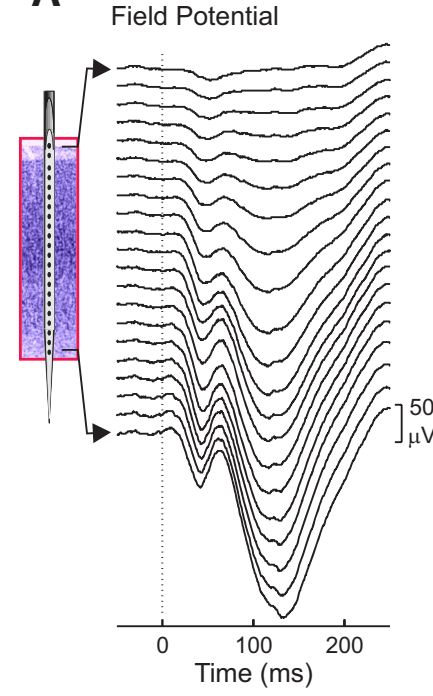

B
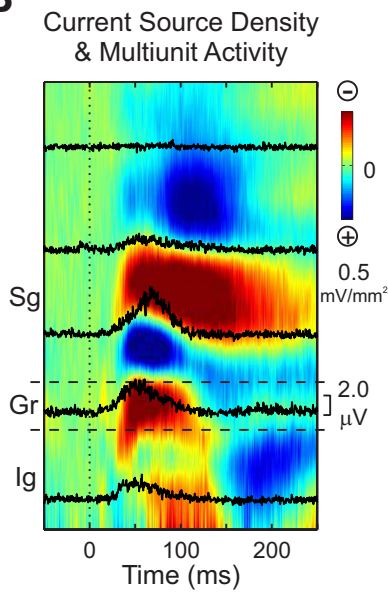

Figure 3. Laminar patterns of trial-averaged auditory responses (50 trials) to the $\mathrm{BF}$ tone (707 Hz, $60 \mathrm{~dB}$ SPL, $100 \mathrm{~ms}$ ) in one representative STG site. $A$, FP responses recorded at 22 depths using a linear array multielectrode (left inset) with $100 \mu \mathrm{m}$ intercontact spacing. $\boldsymbol{B}$, Color plots of the laminar CSD profile derived from FPs shown in $\boldsymbol{A}$. Superimposed black lines are MUA responses at selected channels. Vertical thin lines indicate the stimulus onset.

with concomitant MUA) generally extends over $\sim 2 \mathrm{~mm}$ depth, we can provisionally assign CSD and concomitant MUA features to middle (granular), upper (supragranular), and lower (infragranular) laminar groupings based on the known anatomy of the STG cortex. This is an extension of the procedure used to identify layers in A1 (Lakatos et al., 2007; Kajikawa and Schroeder, 2011, 2015) and is subject to histological verification.

Figure $3 A$ shows a representative example of FP responses recorded simultaneously across the cortical layers at a site in the middle of the STG. The laminar CSD profile derived from this FP profile outlines a laminar activation pattern characterized by a small sink at the estimated depth of layer 4, followed by large source-sink pair in the superficial layers, and by a third current sink below the initial sink in layer 4 (Fig. $3 B$ ). It appears that, qualitatively, the parabelt regions' laminar activation profiles in response to pure tones are comparable to those of core and belt areas (O’Connell et al., 2011).

\section{Mapping of STG}

By presenting 14 different pure tones with frequencies ranging over seven octaves, we found that many STG sites responded to pure tones with distinct spectral preferences. We mapped the best frequency $(\mathrm{BF})$ of MUA responses to pure tones across the STG surface in the two monkeys (Fig. $4 A, B$ ). Figure $5, A$ and $B$, shows layer 4 MUA responses to different tones recorded in two different STG sites labeled with asterisks in Figure 4, $A$ and $B$, respectively. Site A responded best to a $0.5 \mathrm{kHz}$ tone and site $\mathrm{B}$ responded best to a $22 \mathrm{kHz}$ tone. Large portions of STG sites (36 of 45 in Monkey A and 30 of 44 in Monkey B) showed responses to tones with spectral preference.

In both monkeys, the distribution of auditory responsive sites stretched posterior-anteriorly. In Monkey B, the modalities of the cortices flanking the auditory responsive region superiorly and inferiorly were somatosensory-motor and visual, consistent with the known anatomy and physiology of the lateral surface of the temporal lobe. A feature common to the two maps was relatively dense populations of high BF sites in posterior and anterior 
A Monkey A

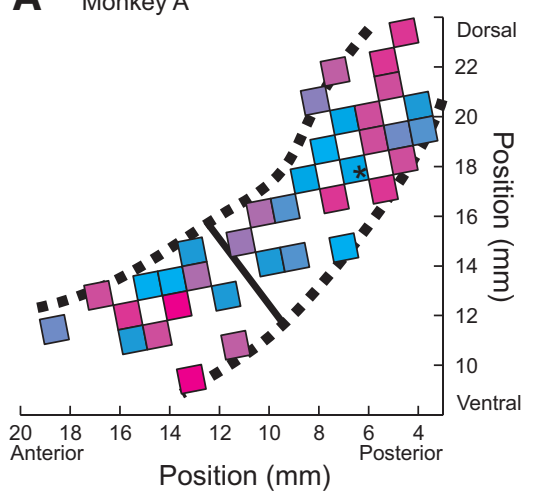

C

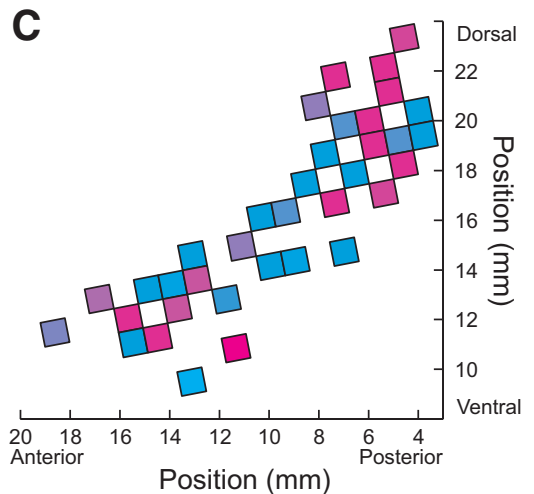

E

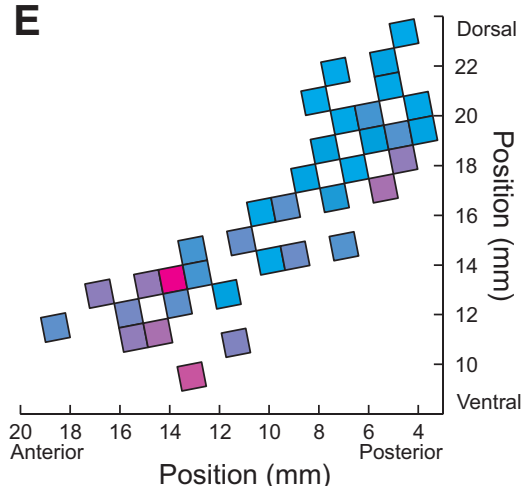

Figure 4. Mapping of the left STG in two monkeys. $\boldsymbol{A}, \boldsymbol{B}$, Tonotopic maps in Monkey $A(\boldsymbol{A})$ and Monkey $B(\boldsymbol{B})$. Grid patterns of recording sites were tilted relative to the stereotaxic axes to indicate the stereotaxic coordinates of the sites. Upper and lower black dotted lines indicate the positions of the LS and STS, respectively. The color of square grids indicates the best frequency (BF). In $\boldsymbol{B}$, yellow and green sites had activity related to somato-sensorimotor or visual events during the behavioral tasks, respectively. Gray-labeled sites responded to sounds other than tones and BPNs. Sites labeled with open squares did not have clear MUA and CSD responses to any sounds we presented. Asterisks in $\boldsymbol{A}$ and $\boldsymbol{B}$ label the exemplar sites of Figure $5, \boldsymbol{A}$ and $\boldsymbol{B}$, respectively. $\boldsymbol{C}, \boldsymbol{D}$, Maps of $B_{B P N}$ in Monkey $A(\boldsymbol{C})$ and Monkey $B(\boldsymbol{D})$. $\boldsymbol{E}, \boldsymbol{F}$, Maps of response latency to the BF tones in Monkey $A(\boldsymbol{E})$ and Monkey $B(\boldsymbol{F})$.
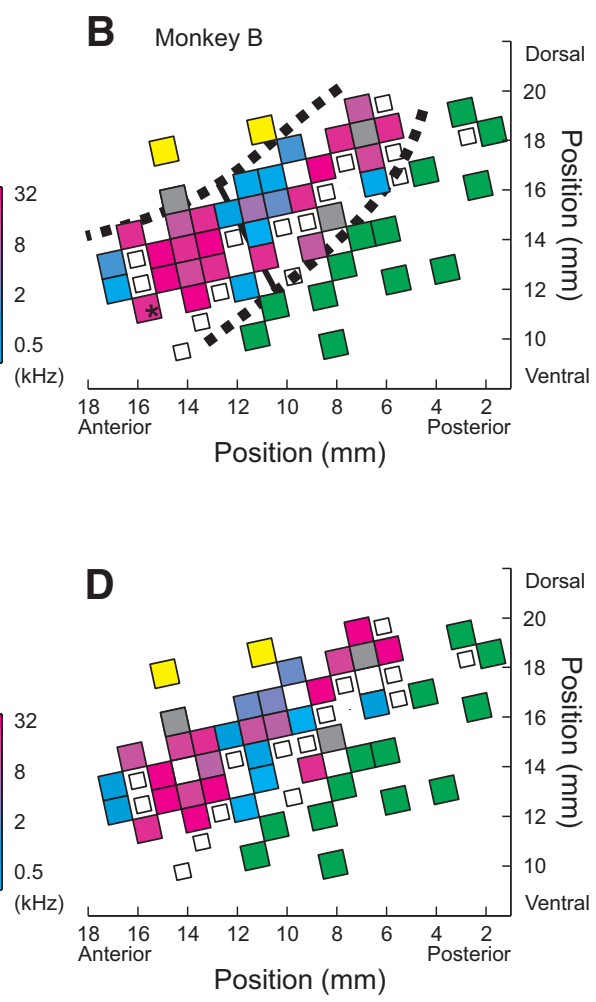

$\mathbf{F}$

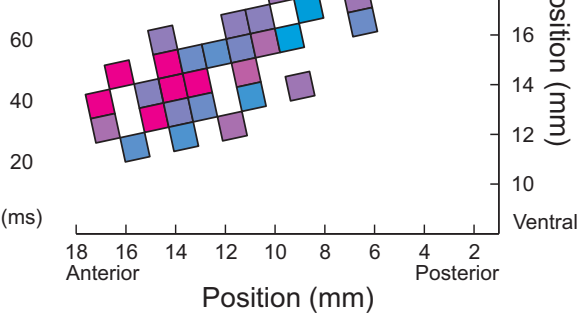

STG. To test the presence of high BF clusters statistically, we calculated the entropy $H$ of binary map indicating whether a site's $\mathrm{BF}$ is at $4 \mathrm{kHz}$ or higher. Whereas the $H$ of Monkey B's map was 25.2 and significantly below those of random patterns ( $p=0.024$, permutation test, $n=1000$ resampling), the $H$ of Monkey A's map, 24.0, was not $(p=0.68)$. These results suggest that the clustering of $\geq 4 \mathrm{kHz}$ sites was significant only in Monkey B. In the map of Monkey A, however, 5 of 6 sites adjoining 4 and 5.6 $\mathrm{kHz}$ sites were of low BF. Therefore, we also examined the clustering of $8 \mathrm{kHz}$ or higher BF in Monkey A. The results indicated that the presence of such clusters in Monkey A reduced $H$ to 19.9, which is marginally significant $(p=0.072)$. Although these results are not conclusive, they suggest an organized representation of acoustic spectra in STG. Separate domains of high $\mathrm{BF}$ in posterior and anterior portions of the STG appear to flank the presumptive border of $\mathrm{A} 1$ and $\mathrm{R}$ around $\sim$ AP10 (Recanzone et al., 2000). This is reminiscent of the tonotopic progressions seen in the core and belt regions.

We examined the gradients of $\mathrm{BF}_{\text {Tone }}$ along STG as was done for the core region (Bendor and Wang, 2008; Scott et al., 2011; Fukushima et al., 2014). To match the shape of fitting to the arching of STG, an arc was fitted to the positions of recording sites $(n=36$ and 30$)$ in each monkey (Fig. $6 A$ ). $\mathrm{BF}_{\text {Tone }}$ values are plotted against angular position (Fig. $6 B$ ). Curves of mean BF showed the patterns of gradients with the reversal across the low $\mathrm{BF}_{\text {Tone }}$ region in both monkeys. We assumed the BF reversal as the border between CPB and RPB. Within each area, linear regressions were calculated to evaluate the linear dependence of $\mathrm{BF}_{\text {Tone }}$ on position (black and gray dotted lines for CPB and RPB, respectively, in Fig. $6 B$ ). Although they were not statistically significant except for Monkey B's RPB, regression coefficients were generally consistent with caudal-to-rostral gradients of highto-low $\mathrm{BF}_{\text {Tone }}$ in $\mathrm{CPB}$ and low-to-high $\mathrm{BF}_{\text {Tone }}$ in RPB.

We also examined responses to $1 / 3$ octave BPN in a large fraction of sites (35 and 25 in Monkeys A and B, respectively). Figure $5, A$ and $B$, shows the pattern of MUA response tuning to tone and BPN center frequencies. Patterns of pure tone and BPN tuning across parabelt sites were similar in these examples (Fig. 5C,D). Across all sites in each monkey (Fig. $5 E, F), \mathrm{BF}_{\mathrm{BPN}}$ correlated significantly with $\mathrm{BF}_{\text {Tone }}$ (Pearson's correlation coefficient: $r=0.91$ and 0.94 for monkeys A and B, $p<10^{-10}$ in both monkeys). Therefore, the spectral tuning for pure tones and BPN is similar across sites in the parabelt (Fig. $4 C, D$ ), as it is in core and belt areas (Rauschecker and Tian, 2004; Kusmierek and Rauschecker, 2009; Kajikawa et al., 2011). The entropy of a binary map indicating whether a site's $\mathrm{BF}_{\mathrm{BPN}}$ was at $4 \mathrm{kHz}$ or higher for Monkey $B$ was 24.0 and significantly below those of random patterns ( $p=$ $0.001)$. In Monkey A's map, whether a site's $\mathrm{BF}_{\mathrm{BPN}}$ is at $8 \mathrm{kHz}$ or higher, was 20.2, and not significantly different from those of random patterns $(p=0.53)$. The results indicated the presence of high $\mathrm{BF}_{\mathrm{BPN}}$ clusters was significant only in Monkey $\mathrm{B}$. Gradients of $\mathrm{BF}_{\mathrm{BPN}}$ along STG generally aligned with those of $\mathrm{BF}_{\text {Tone }}$ and the positions of tonotopic reversal across low $\mathrm{BF}_{\mathrm{BPN}}$ region were similar to those of $\mathrm{BF}_{\text {Tone }}$ (Fig. 6C).

We compared the magnitudes of the MUA responses to pure tones, $1 / 3$ octave BPN, and BBN. Median magnitudes of responses to 3 sounds were $0.57,0.67$, and $0.62 \mu \mathrm{V}(n=36,35$, and 33) in Monkey A and 0.36, 0.43, and $0.29 \mu \mathrm{V}(n=31,25$ and 26) 
A

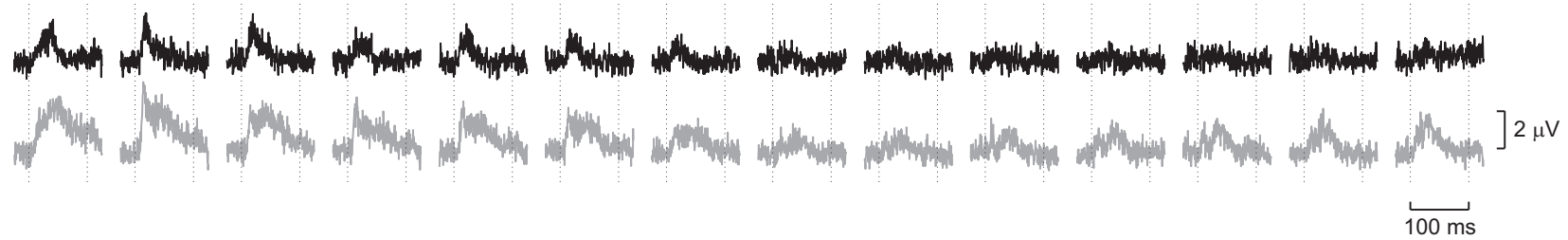

B
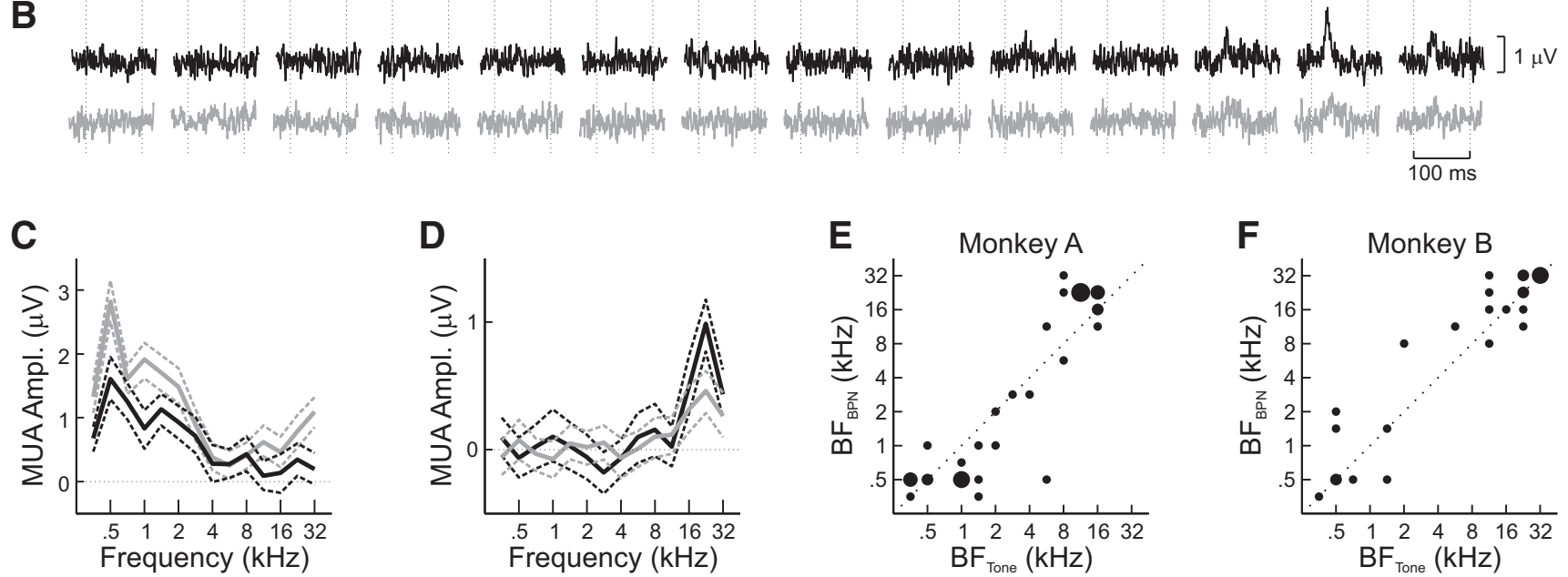

Figure 5. Spectrally tuned responses in STG. $\boldsymbol{A}, \boldsymbol{B}$, Tone-evoked (black) and BPN-evoked (gray) MUA responses from the middle layers at two example sites $(\boldsymbol{A}, \boldsymbol{B})$. All time bases extend from -25 to $125 \mathrm{~ms}$ relative to the onset of $100 \mathrm{~ms}$ sounds. Tone frequencies and BPN center frequencies are indicated on the top row $(\mathrm{kHz})$. $C$, Tuning curves plotting mean amplitudes of MUA responses to tones (black) and BPN (gray) shown in $\boldsymbol{A}$. Dotted lines show $95 \%$ confidence intervals (bootstrap, 1000 resampling). $\boldsymbol{D}$, Tuning curves of MUA responses shown in $\boldsymbol{B}$ in the same format as $\boldsymbol{C}$. $\boldsymbol{E}$, Plot of $\mathrm{BF}_{\mathrm{BPN}}$ against $\mathrm{BF}_{\text {Tone }}$ in Monkey A. $\boldsymbol{F}$, Plot of $\mathrm{BF}_{\mathrm{BPN}}$ against $\mathrm{BF}_{\text {Tone }}$ in Monkey $\mathrm{B}$.

in Monkey B (Fig. 7A). Median BPN responses did not significantly differ from median tone responses in either monkey (Wilcoxon signed-rank test, $z=0.20, p=0.23$ for Monkey A and $z=$ $0.014, p=0.98$ for Monkey B). Similarly, median BBN responses did not significantly differ from median tone responses in either monkey $(z=1.44, p=0.15$ for Monkey A and $z=-0.83, p=$ 0.41 for Monkey B). However, the relative magnitudes of responses to the 3 types of stimuli depended on recording sites. Several sites responded significantly more strongly or weakly to $\mathrm{BPN}$ or BBN compared with tone (bootstrap $p<0.05$ ), whereas for the majority of sites, neither BPN nor BBN response magnitudes were significantly different from tone response magnitude (Fig. $7 B$ ). These results suggest that spectral envelope preferences may differ between sites and that none of spectral envelope categories that we tested dominates the representation in the macaque parabelt.

The distributions of response latency to BF tones are mapped in Figure 4, $C$ and D. Many posterior sites in Monkey A responded to $\mathrm{BF}$ tones with relatively short latencies of $<30 \mathrm{~ms}$, whereas most latencies longer than $30 \mathrm{~ms}$ were found in the more anterior recording sites. Although fewer sites with latencies shorter than $30 \mathrm{~ms}$ were found in Monkey B, sites with longer latencies were found mostly in anterior half of recording sites. Therefore, in both monkeys, the density of sites with longer latencies was higher in more anterior loci.

Based on the progression of auditory cortical stages from medial to lateral, longer latencies in STG sites closer to STS than LS might also be expected. We examined the gradients of latencies along both the posterior-anterior and the dorsal-ventral orien- tations (Fig. 6A). Latencies are plotted for the posterior-anterior orientation in Figure 6D and the correlation of latency with distance along the anterior-posterior dimension was significant in both monkeys (Pearson's correlation coefficient: $r=-0.61$ for Monkey A and -0.47 for Monkey B, both $p<0.01$ ). For the dorsal-ventral dimension, correlation coefficients, $r=-0.21$ for Monkey A and 0.21 for Monkey B, were not significant ( $p=0.23$ and 0.25 , respectively) in either monkey (Fig. $6 E$ ). Therefore, although responses were delayed more in rostral than caudal parabelt, no change in latency from dorsal to ventral STG was detected.

Median latencies of $\mathrm{CPB}$ and $\mathrm{RPB}$ sites were 13.5 and $31 \mathrm{~ms}$ in Monkey A and 28.8 and $40.5 \mathrm{~ms}$ in Monkey B. In both monkeys, the latencies in RPB were significantly longer than those in $\mathrm{CPB}$ (Wilcoxon rank-sum test, $p<0.05$ ). For comparison, median A1 and CM response latencies to BF tones at $70 \mathrm{~dB}$ SPL reported in a study using similar techniques were 9 and $12 \mathrm{~ms}$, respectively (Lakatos et al., 2005). Between the two monkeys, latency in CPB was significantly shorter in Monkey A than Monkey B ( $p=$ $0.0019)$, whereas not significantly different in RPB $(p=0.092)$, suggesting large intersubject variability of response latencies in parabelt.

Response latency to $\mathrm{BF}$ tones was found to be longer in RPB than СРB. There are two anatomical connection patterns that support the caudal to rostral gradient of latency. One is that parabelt areas inherit the gradient present within the belt region. The other is an additional hierarchy within the parabelt region, from the caudal parabelt to rostral parabelt area (Hackett, 2011; Camalier et al., 2012; Hackett et al., 2014). Both possibilities are 
A

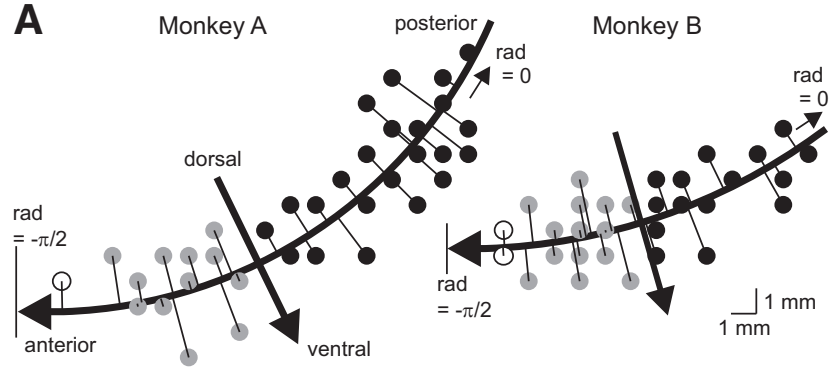

B

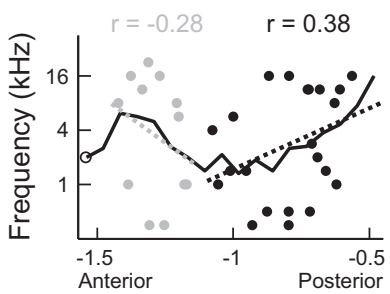

Angular position (rad)

C
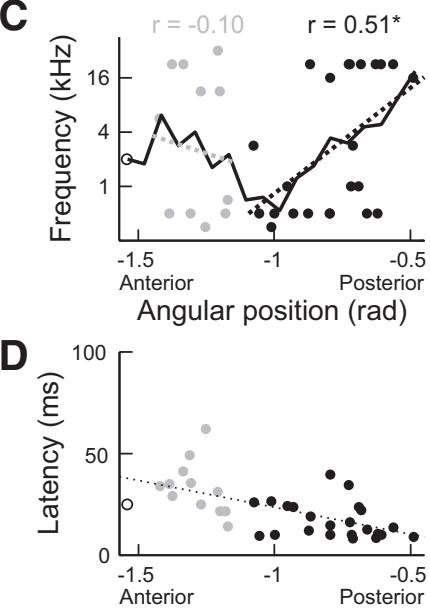

Angular position (rad)

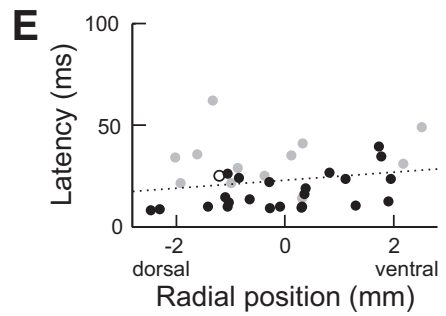

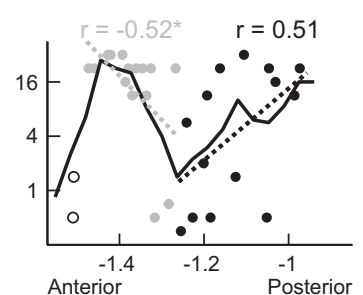

Angular position (rad)
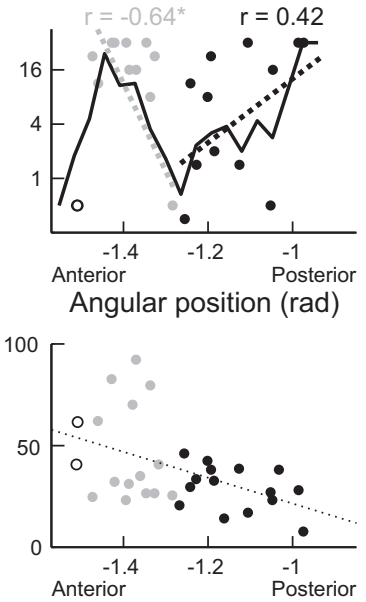

Angular position (rad)

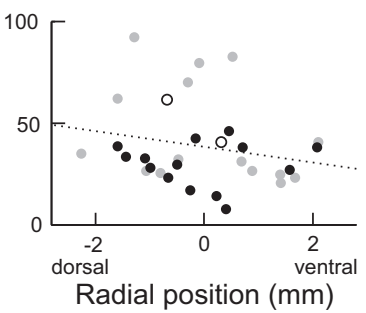

Figure 6. Distributions of the tone response latencies over the surface of the STG. In all panels, left and right columns represent data from Monkey $A$ and Monkey B, respectively. A, Polar coordinate expression of recording sites. Black filled circles are the positions of recording sites in CPB. Gray filled circles and unfilled circles are the positions of recording sites in RPB. Curved and radial thick lines are the arcs fitted to the positions and putative position of the border between CPB and RPB. Arrowheads indicate counterclockwise and outward directions of angular and radial axes, respectively. Thin radial lines represent radial projections of the recording sites onto the arcs. $B, \mathrm{BF}_{\text {Tone }}$ are plotted against the angular positions on the fitted arcs. Black line shows a curve of mean $\mathrm{BF}_{\text {Tone }}$ derived by moving bins. Black and gray dotted lines are linear regression lines for all CPB sites and RPB sites, except for anterior RPB sites of unfilled circles. $C, B_{B P N}$ values are plotted against the angular positions. $\ln B$ and $C$, numbers above the plots depict regression coefficients and asterisks indicate significant linear dependence of $B F$ on position $(p<0.05)$. $\boldsymbol{D}$, Latencies are plotted against the angular positions. $E$, Latencies are plotted against the radial positions from the fitted arcs. In $\boldsymbol{D}$ and $\boldsymbol{E}$, dotted lines are regression lines calculated for all sites.

consistent with "feedforward" pattern of activation starting at the layer 4 in RPB.

The gradient of response latencies from $\mathrm{CPB}$ to RPB contrasts with a recent human study that found shortest latency of electro-

A
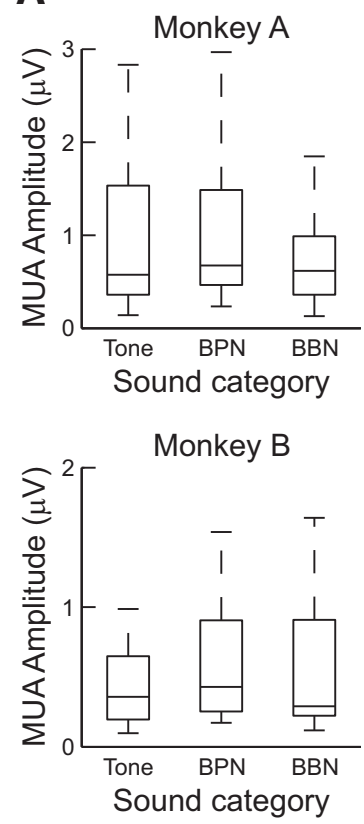

B

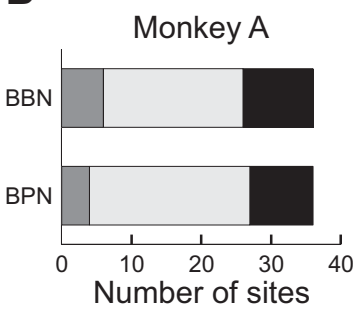

Monkey B

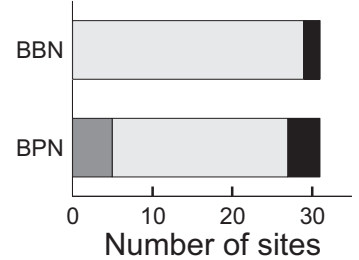

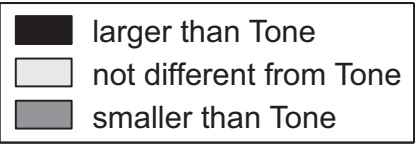

Figure 7. Comparisons of response magnitudes between sounds. $A$, Boxplots show median and quartile magnitudes of responses to pure tones (Tone), $1 / 3$ octave BPN and BBN. $\boldsymbol{B}, \mathrm{Bar}$ graphs show the number of sites in which the responses to BPN and BBN were significantly larger than (black), not significantly different from (light gray), and significantly smaller than (gray) responses to pure tones based on bootstrap (1000 resample, $p<0.05$ ).

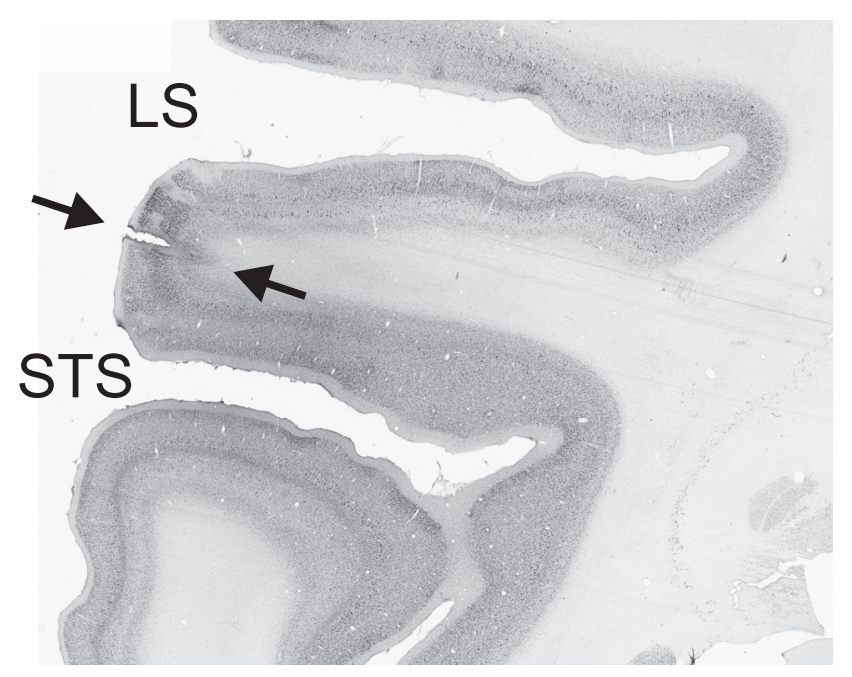

Figure 8. Coronal section from Monkey A. Arrows flank a penetration into the CPB.

corticographic (ECoG) responses to click and vowel sounds in the middle portion of STG (Nourski et al., 2014a). Although experimental conditions differ from the present study, the pattern of findings in humans suggests that the specific anatomical arrangement of $\mathrm{PB}$ areas differs between the species and/or that there may be an additional higher-order region in the human that either does not exist or has not yet been detected in the macaque.

\section{Histological confirmation of electrode tracks}

Penetrations into the STG at nearly right angles in Monkey A were confirmed in coronal sections of the brain. In Figure 8, a track of one penetration that went to the middle of the STG can be seen (arrows). Parts of adjacent penetration tracks are also 
visible. Some tracks were observed penetrating into the ITG and the upper bank of the LS (not shown in Fig. 8). Most penetrations were made nearly perpendicular to the surface of those gyri; recordings from penetrations tangential to the layers in the sulci above and below the STG were excluded from analysis.

\section{Discussion}

We report the first systematic study of neuron response properties of the parabelt region of auditory cortex in the STG of awake macaques. Our study used a novel, direct approach to the surface of the STG that required a new surgical strategy and customdesigned recording chambers. Initial survey of the STG yielded several surprising findings. Based on earlier reports, we expected that parabelt neurons would be poorly responsive to passive (i.e., task-irrelevant) auditory stimulus presentation of pure tones. Contrary to these expectations, our results show that neuron ensembles throughout the parabelt region are responsive in awake, even passive, subjects and that they respond robustly to pure tones. Our findings also suggest the presence of organized spectral representation in the parabelt areas that may mirror the organization of the tonotopic gradients in the adjacent belt regions of auditory cortex (Rauschecker et al., 1995; Romanski et al., 1999a). Therefore, the tonotopic gradients established in the A1 and rostral areas of the auditory "core" may extend into the parabelt in macaques, as suggested in humans (Humphries et al., 2010; Woods et al., 2010; Striem-Amit et al., 2011).

\section{Technical considerations}

Several recent studies of unit recordings approached the STG indirectly by crossing the LS vertically in awake macaques, which presumably required fine control of penetration angle of electrodes traveling over long distance to reach the cortex (Russ et al., 2008; Tsunada et al., 2011; Camalier et al., 2012). Such methods leave uncertainty about the laminar position of recording sites and whether they were in the lateral belt or the parabelt region. To make basic characterizations of the STG (e.g., topographic mapping, identifying specific cortical layers' activity, and tracer injections into physiologically defined sites), a better approach would be to make multiple penetrations oriented perpendicular to cortical laminae.

Other studies mapped portions of the STG directly in anesthetized macaques (Rauschecker et al., 1995; Romanksi et al., 1999a; Tian et al., 2001). In these studies, most of the penetrations were concentrated in the dorsal aspect of the STG encompassing the edge of the lateral belt region. Those recordings showed evidence of tonotopic organization, as well as selective responsiveness to spatial versus nonspatial categories of acoustic stimuli. Given its position in the anatomical hierarchy (Hackett et al., 1998a; Hackett, 2011), it was expected that the parabelt region would also be engaged in signal processing of higher-level auditory attributes (Wollberg and Newman, 1972; Newman and Wollberg, 1973; Glass and Wollberg, 1983; Rauschecker et al., 1995; Smith et al., 2013) and influenced by cognitive states (e.g., attention). Therefore, it was desirable to establish a technique that allowed recordings from the entire extent of STG to explore the properties of parabelt areas in awake subjects.

The methods developed in the present study minimized the limitations imposed by anesthesia and suboptimal electrode mapping strategy. The results indicate that direct approach orthogonal to the surface and layers of the STG is a promising method to study these regions. A topographic distribution of any response properties would guide further exploration (e.g., the study of interactions between loci of similar properties). Direct exploration of the STG can be used to compare with the findings of fMRI studies and the addition of behavioral manipulations allows the assessment of the influence of behavioral states on response properties. The approach in macaques also permits comparison of the parabelt with the lateral belt areas, which are partly located on the STG surface.

One consequence of implanting a chamber directly over the STG is its potential influence on acoustic and spatial filtering by the subject's head due to its proximity to a pinna. In the present study, the right ear contralateral to the implanted chamber was devoid of this type of chamber that may have reduced such compromise. However, to study the spatial coding in STG, it will be necessary to measure the head-related transfer functions (HRTFs) before the implant for each monkey and to deliver sounds filtered by the HRTF through earphones (Spezio et al., 2000).

It is noteworthy that the methods we developed for this study open up several additional possibilities. One is more direct mapping of the insular cortex, inferior temporal gyrus, and a number of subcortical structures, all of which have pial surfaces relatively parallel to that of the STG. Other avenues of research are also made possible by our direct approach; for example, direct imaging such as intrinsic optical signals or activity-indicating fluorescent dye signals of the STG and surrounding regions (Grinvald et al., 1991; Grinvald and Hildesheim, 2004; Sit et al., 2009).

\section{Auditory properties of the parabelt}

When tones were effective in evoking robust MUA responses, laminar CSD activation patterns reminiscent of upstream cortices were observed in the STG. This suggests that the parabelt regions share the general scheme of sensory cortical activation initiated at the thalamocortical projection-recipient layer $3 \mathrm{~b} / 4$. In the belt and parabelt, the thalamorecipient laminae receive thalamic afferents mainly originating from dorsal nucleus of the medial geniculate (MGd) (Burton and Jones, 1976; Hackett and de la Mothe, 2009) and inputs to layer 4 from lower cortical areas (Hackett et al., 2014). Our findings pose questions about the differential roles of thalamocortical afferents and corticocortical projections from belt areas and prompt additional investigation. Given that thalamic and upstream cortical inputs preferentially target the superficial and middle layers (Jones and Burton, 1976; Romanski et al., 1999b) and that these inputs are proposed to have distinct roles in information processing (Jones, 1998; Lakatos et al., 2007), it will be important to distinguish their influences at the level of the cortical columnar neuron ensemble using laminar activity profile analysis.

There are no previous anatomical or physiological studies that have addressed tonotopic organization of the parabelt directly. Within and between core and belt regions, interareal connections have preferential weight between tonotopically matched zones (Morel et al., 1993; Lee et al., 2004). The CPB and RPB have topographic connections with belt areas, but the connection patterns are not specific enough to determine whether those connections favor tonotopically matched locations in belt/parabelt (Hackett et al., 1998a; Hackett et al., 2014). The connections with the MGd are not informative either because MGd is not organized tonotopically (Hackett et al., 1998b). These anatomical findings so far suggest that the tonotopic organization of the parabelt areas might be less orderly than in core or belt regions.

In contrast, mapping results in the present study suggest the clustering of high BF sites at posterior and anterior parts of STG. Even though gradient patterns were not as clear as the core and belt regions, the portion flanked by high-frequency representations was occupied by relatively low-frequency representations, 
suggesting the putative border between the caudal and rostral parabelt areas. That suggests, in turn, that the parabelt region has tonotopic gradients parallel to those of the core and belt regions. It should be noted that the distances between the caudal and rostral high-frequency zones differed between two monkeys. Additional mapping in more animals will properly gauge the degree of variability in these representations, as well as the extent to which the tonotopic organization of the macaque STG parallels that of Heschl's gyrus in humans, as suggested by functional imaging and ECoG studies (Woods et al., 2009, 2010; Nourski et al., 2014b).

Our results indicate that, although the parabelt region may exhibit preferential processing of complex sounds such as vocalizations (Gross et al.,1967; Leinonen et al., 1980), its distributed response patterns appear to follow the spectral content of sounds to some degree. Earlier studies suggested that BPNs evoke stronger responses than tones in belt areas (Rauschecker et al., 1995; Rauschecker and Tian, 2004; Petkov et al., 2006) and showed bandwidth tuning (Rauschecker et al., 1995; Rauschecker and Tian, 2004) or harmonic sound preference (Kikuchi et al., 2014). Our findings indicate spectral tuning in parabelt areas, but do not indicate a preference for BPN over pure tones. We did not investigate bandwidth tuning or harmonic representations. Further studies are needed to examine the representations of those features systematically in the parabelt.

The present study explored only the left STG. Considering the functional organization of sensory cortices in general, it is likely that the parabelt on the right STG is also organized as the parabelt in the left STG. However, the representation of other features may differ between hemispheres. Application of our technique to both sides of STG in awake subjects would also help understanding the mechanistic difference that supports different functions of hemispheres.

Given its position in the auditory processing hierarchy, the parabelt is thought to be more involved in cognitive functions than lower-level auditory areas. Of particular interest for future studies would be vocalization perception, especially considering possible correspondence of the parabelt region to the human STG (Hackett, 2003, 2007). In visual systems, higher cognitive cortices such as the inferior temporal cortex maintain crude versions of the spatiotopic patterns originating in the receptor surface in the retinae. Similar organization principles may apply to the parabelt, where cortical areas devoted to higher cognitive processing also maintain spectral relationships like those noted on the receptor surface in the cochleae.

\section{References}

Ahveninen J, Jääskeläinen IP, Raij T, Bonmassar G, Devore S, Hämäläinen M, Levänen S, Lin FH, Sams M, Shinn-Cunningham BG, Witzel T, Belliveau JW (2006) Task-modulated "what" and "where" pathways in human auditory cortex. Proc Natl Acad Sci U S A 103:14608-14613. CrossRef Medline

Bendor D, Wang X (2008) Neural response properties of primary, rostral, and rostrotemporal core fields in the auditory cortex of marmoset monkeys. J Neurophysiol 100:888-906. CrossRef Medline

Binder JR, Liebenthal E, Possing ET, Medler DA, Ward BD (2004) Neural correlates of sensory and decision processes in auditory objectidentification. Nat Neurosci 7:295-301. CrossRef Medline

Buchsbaum BR, Olsen RK, Koch P, Berman KF (2005) Human dorsal and ventral auditory streams subserve rehearsal-based and echoic processes during verbal working memory. Neuron 48:687-697. CrossRef Medline

Burton H, Jones EG (1976) The posterior thalamic region and its cortical projection in new world and old world monkeys. J Comp Neurol 168: 249-301. CrossRef Medline

Calvert GA, Bullmore ET, Brammer MJ, Campbell R, Williams SC, McGuire
PK, Woodruff PW, Iversen SD, David AS (1997) Activation of auditory cortex during silent lipreading. Science 276:593-596. CrossRef Medline

Camalier CR, D'Angelo WR, Sterbing-D'Angelo SJ, de la Mothe LA, Hackett TA (2012) Neural latencies across auditory cortex of macaque support a dorsal-stream supramodal timing advantage in primates. Proc Natl Acad Sci U S A 109:18168-18173. CrossRef Medline

Chernov N (2010) Circular and linear regression: fitting circles and lines by least squares. Chapman and Hall/CRC monographs on statistics and applied probability 117. Boca Raton, FL: CRC.

Frey S, Pandya DN, Chakravarty MM, Bailey L, Petrides M, Collins DL (2011) An MRI based average macaque monkey stereotaxic atlas and space (MNI monkey space). Neuroimage 55:1435-1442. CrossRef Medline

Fukushima M, Saunders RC, Leopold DA, Mishkin M, Averbeck BB (2014) Differential coding of conspecific vocalizations in the ventral auditory cortical stream. J Neurosci 34:4665-4676. CrossRef Medline

Fullerton BC, Pandya DN (2007) Architectonic analysis of the auditoryrelated areas of the superior temporal region in human brain. J Comp Neurol 504:470-498. CrossRef Medline

Glass I, Wollberg Z (1983) Responses of cells in the auditory cortex of awake squirrel monkeys to normal and reversed species-specific vocalizations. Hear Res 9:27-33. CrossRef Medline

Grinvald A, Hildesheim R (2004) VSDI: a new era in functional imaging of cortical dynamics. Nat Rev Neurosci 5:874-885. CrossRef Medline

Grinvald A, Frostig RD, Siegel RM, Bartfeld E (1991) High-resolution optical imaging of functional brain architecture in the awake monkey. Proc Natl Acad Sci U S A 88:11559-11563. CrossRef Medline

Gross CG, Schiller PH, Wells C, Gerstein GL (1967) Single-unit activity in temporal association cortex of the monkey. J Neurophysiol 30:833-843. Medline

Hackett TA (2003) The comparative anatomy of the primate auditory cortex. In: Primate audition: ethology and neurobiology (Ghazanfar AA, ed), pp 199-226. Boca Raton, FL: CRC.

Hackett TA (2007) Organization and correspondence of the auditory cortex of human and nonhuman primates. In: Evolution of the nervous system (Kaas JH, ed), pp 109-119. Oxford, Elsevier.

Hackett TA (2008) Anatomical organization of the auditory cortex. J Am Acad Audiol 19:774-779. CrossRef Medline

Hackett TA (2011) Information flow in the auditory cortical network. Hear Res 271:133-146. CrossRef Medline

Hackett TA, de la Mothe LA (2009) Regional and laminar distribution of the vesicular glutamate transporter, VGluT2, in the macaque monkey auditory cortex. J Chem Neuroanat 38:106-116. CrossRef Medline

Hackett TA, Stepniewska I, Kaas JH (1998a) Subdivisions of auditory cortex and ipsilateral cortical connections of the parabelt auditory cortex in macaque monkeys. J Comp Neurol 394:475-495. CrossRef Medline

Hackett TA, Stepniewska I, Kaas JH (1998b) Thalamocortical connections of the parabelt auditory cortex in macaque monkeys. J Comp Neurol 400:271-286. CrossRef Medline

Hackett TA, Stepniewska I, Kaas JH (1999) Prefrontal connections of the parabelt auditory cortex in macaque monkeys. Brain Res 817:45-58. CrossRef Medline

Hackett TA, de la Mothe LA, Camalier CR, Falchier A, Lakatos P, Kajikawa Y, Schroeder CE (2014) Feedforward and feedback projections of caudal belt and parabelt areas of auditory cortex: refining the hierarchical model. Front Neurosci 8;72. CrossRef Medline

Humphries C, Liebenthal E, Binder JR (2010) Tonotopic organization of human auditory cortex. Neuroimage 50:1202-1211. CrossRef Medline

Johnson JA, Zatorre RJ (2005) Attention to simultaneous unrelated auditory and visual events: behavioral and neural correlates. Cereb Cortex 15:1609-1620. CrossRef Medline

Jones EG (1998) The core and matrix of thalamic organization. Neuroscience 85:331-345. CrossRef Medline

Jones EG, Burton H (1976) Areal differences in the laminar distribution of thalamic afferents in cortical fields of the insular, parietal and temporal regions of primates. J Comp Neurol 168:197-247. CrossRef Medline

Kaas JH, Hackett TA (2000) Subdivisions of auditory cortex and processing streams in primates. Proc Natl Acad Sci U S A 97:11793-11799. CrossRef Medline

Kajikawa Y, Schroeder CE (2011) How local is the local field potential? Neuron 72:847-858. CrossRef Medline

Kajikawa Y, Schroeder CE (2015) Generation of field potentials and modu- 
lation of their dynamics through volume integration of cortical activity. J Neurophysiol 113:339-351. Medline

Kajikawa Y, Camalier CR, de la Mothe LA, D'Angelo WR, Sterbing-D'Angelo SJ, Hackett TA (2011) Auditory cortical tuning to band-pass noise in primate A1 and CM: a comparison to pure tones. Neurosci Res 70:401407. CrossRef Medline

Kikuchi Y, Horwitz B, Mishkin M, Rauschecker JP (2014) Processing of harmonics in the lateral belt of macaque auditory cortex. Front Neurosci 8:204. CrossRef Medline

Kusmierek P, Rauschecker JP (2009) Functional specialization of medial auditory belt cortex in the alert rhesus monkey. J Neurophysiol 102:16061622. CrossRef Medline

Lakatos P, Pincze Z, Fu KM, Javitt DC, Karmos G, Schroeder CE (2005) Timing of pure tone and noise-evoked responses in macaque auditory cortex. Neuroreport 16:933-937. CrossRef Medline

Lakatos P, Chen CM, O'Connell MN, Mills A, Schroeder CE (2007) Neuronal oscillations and multisensory interaction in primary auditory cortex. Neuron 53:279-292. CrossRef Medline

Leaver AM, Rauschecker JP (2010) Cortical representation of natural complex sounds: effects of acoustic features and auditory object category. J Neurosci 30:7604-7612. CrossRef Medline

Lee CC, Imaizumi K, Schreiner CE, Winer JA (2004) Concurrent tonotopic processing streams in auditory cortex. Cereb Cortex 14:441-451. CrossRef Medline

Leff AP, Schofield TM, Crinion JT, Seghier ML, Grogan A, Green DW, Price CJ (2009) The left superior temporal gyrus is a shared substrate for auditory short-term memory and speech comprehension: evidence from 210 patients with stroke. Brain 132:3401-3410. CrossRef Medline

Leinonen L, Hyvärinen J, Sovijärvi AR (1980) Functional properties of neurons in the temporo-parietal association cortex of awake monkey. Exp Brain Res 39:203-215. Medline

Mesgarani N, Cheung C, Johnson K, Chang EF (2014) Phonetic feature encoding in human superior temporal gyrus. Science 343:1006-1010. CrossRef Medline

Morel A, Garraghty PE, Kaas JH (1993) Tonotopic organization, architectonic fields, and connections of auditroy cortex in macaque monkeys. J Comp Neurol 335:437-459. CrossRef Medline

Munoz-Lopez MM, Mohedano-Moriano A, Insausti R (2010) Anatomical pathways for auditory memory in primates. Front Neuroanat 4:129. Medline

Newman JD, Wollberg Z (1973) Multiple coding of species-specific vocalizations in the auditory cortex of squirrel monkeys. Brain Res 54:287-304. CrossRef Medline

Nourski KV, Steinschneider M, McMurray B, Kovach CK, Oya H, Kawasaki H, Howard MA 3rd (2014a) Functional organization of human auditory cortex: Investigation of response latencies through direct recordings. Neuroimage 101:598-609. CrossRef Medline

Nourski KV, Steinschneider M, Oya H, Kawasaki H, Jones RD, Howard MA (2014b) Spectral organization of the human lateral superior temporal gyrus revealed by intracranial recordings. Cereb Cortex 24:340-352. CrossRef Medline

O'Connell MN, Falchier A, McGinnis T, Schroeder CE, Lakatos P (2011) Dual mechanism of neuronal ensemble inhibition in primary auditory cortex. Neuron 69:805-817. CrossRef Medline

Paxinos G, Huang XF, Petrides M, Toga AW (2008) The rhesus monkey brain in stereotaxic coordinates, Ed 2. San Diego: Academic.

Petkov CI, Kang X, Alho K, Bertrand O, Yund EW, Woods DL (2004) Attentional modulation of human auditory cortex. Nat Neurosci 7:658663. CrossRef Medline

Petkov CI, Kayser C, Augath M, Logothetis NK (2006) Functional imaging reveals numerous fields in the monkey auditory cortex. PLoS Biol 4:e215. CrossRef Medline
Rauschecker JP, Scott SK (2009) Maps and streams in the auditory cortex: nonhuman primates illuminate human speech processing. Nat Neurosci 12:718-724. CrossRef Medline

Rauschecker JP, Tian B (2000) Mechanisms and streams for processing of "what" and "where" in auditory cortex. Proc Natl Acad Sci U S A 97: 11800-11806. CrossRef Medline

Rauschecker JP, Tian B (2004) Processing of band-passed noise in the lateral auditory belt cortex of the rhesus monkey. J Neurophysiol 91:2578-2589. CrossRef Medline

Rauschecker JP, Tian B, Hauser M (1995) Processing of complex sounds in the macaque nonprimary auditory cortex. Science 268:111-114. CrossRef Medline

Recanzone GH, Guard DC, Phan ML (2000) Frequency and intensity response properties of single neurons in the auditory cortex of the behaving macaque monkey. J Neurophysiol 83:2315-2331. Medline

Romanski LM, Giguere M, Bates JF, Goldman-Rakic PS (1997) Topographic organization of medial pulvinar connections with the prefrontal coretex in the rhesus monkey. J Comp Neurol 379:313-332. CrossRef Medline

Romanski LM, Tian B, Fritz J, Mishkin M, Goldman-Rakic PS, Rauschecker JP (1999a) Dual streams of auditory afferents target multiple domains in the primate prefrontal cortex. Nat Neurosci 2:1131-1136. CrossRef Medline

Romanski LM, Bates JF, Goldman-Rakic PS (1999b) Auditory belt and parabelt projections to the prefrontal cortex in the rhesus monkey. J Comp Neurol 403:141-157. CrossRef Medline

Russ BE, Ackelson AL, Baker AE, Cohen YE (2008) Coding of auditorystimulus identity in the auditory non-spatial processing stream. J Neurophysiol 99:87-95. Medline

Scott BH, Malone BJ, Semple MN (2011) Transformation of temporal processing across auditory cortex of awake macaques. J Neurophysiol 105: 712-730. CrossRef Medline

Sit YF, Chen Y, Geisler WS, Miikkulainen R, Seidemann E (2009) Complex dynamics of V1 population responses explained by a simnple gaincontrol model. Neuron 64:943-956. CrossRef Medline

Smith E, Kellis S, House P, Greger B (2013) Decoding stimulus identity from multi-unit activity and local field potentials along the ventral auditory stream in the awake primate: implications for cortical neural prostheses. J Neural Eng 10:016010. CrossRef Medline

Spezio ML, Keller CH, Marrocco RT, Takahashi TT (2000) Head-related transfer functions of the rhesus monkey. Hear Res 144:73-88. CrossRef Medline

Striem-Amit E, Hertz U, Amedi A (2011) Extensive cochleotopic mapping of human auditory cortical fields obtained with phase-encoding fMRI. PLoS One 6:e17832. CrossRef Medline

Sweet RA, Dorph-Petersen KA, Lewis DA (2005) Mapping auditory core, lateral belt and parabelt cortices in the human superior temporal gyrus. J Comp Neurol 491:270-289. CrossRef Medline

Tian B, Reser D, Durham A, Kustov A, Rauschecker JP (2001) Functional specialization in rhesus monkey auditory cortex. Science 292:290-293. CrossRef Medline

Tsunada J, Lee JH, Cohen YE (2011) Representation of speech categories in the primate auditory cortex. J Neurophysiol 105:2634-2646. Medline

Wollberg Z, Newman JD (1972) Auditory cortex of squirrel monkey: response patterns of single cells to species-specific vocalizations. Science 175:212-214. CrossRef Medline

Woods DL, Stecker GC, Rinne T, Herron TJ, Cate AD, Yund EW, Liao I, Kang X (2009) Functional maps of human auditory cortex: effects of acoustic features and attention. PLoS One 4:e5183. CrossRef Medline

Woods DL, Herron TJ, Cate AD, Yund EW, Stecker GC, Rinne T, Kang X (2010) Functional properties of human auditory cortical fields. Front Syst Neurosci 4:155. CrossRef Medline 